\title{
From training to learning: Transition of a workplace for industry 4.0
}

\author{
Bordin Rassameethes $^{\mathrm{a}}$, Kongkiti Phusavat ${ }^{\mathrm{a}, *}$, Zbigniew Pastuszak $^{\mathrm{b}}$, Achmad Nizar Hidayanto $^{\mathrm{c}}$ \\ and Jukka Majava ${ }^{\mathrm{d}}$ \\ ${ }^{a}$ Kasetsart University, Thailand \\ ${ }^{\mathrm{b}}$ Maria Curie-Sklodowska University, Poland \\ ${ }^{\mathrm{c}}$ Universitas Indonesia, Indonesia \\ ${ }^{\mathrm{d} O u l u}$ University, Finland
}

Received 31 July 2021

Accepted 28 September 2021

\begin{abstract}
.
BACKGROUND: Transition into Industry 4.0 has had many significant impacts. Customization symbolizes leanness, flexibility, adaptability, and agility. A business operator needs to recognize the factors that contribute to better utilization of the talents of its workforce and more effective workplace learning.

OBJECTIVE: The study aims to provide a construct which highlights effective workplace learning. In this context, a construct represents a broad view of various interrelated ideas and concepts which can point to academic and practical implications.

METHODS: The study applies action research which is suitable when observing a transformative change. The study intends to observe and notice how the environmental factors have changed and try to predict their impacts on human capital development. To help verify the suitability of these impacts, a comparison with similar studies or findings is made. Focuses on literature reviews which look at the impacts from Industry 4.0 (on a need to tackle the waste of the talents in a workplace), recent developments of learning (on an emerging importance of informal learning), and survey's data (on a shift in a workplace's expectation on the workers).

RESULTS: Workplace learning has gradually replaced training and education. The proposed construct can help tackle the underutilization of the talents in a workplace as the workers are nowadays expected to perform the tasks and learn at the same time.

CONCLUSIONS: Sustaining learning in a workplace needs to understand behavior, motivation, emotion, and workplace engagement. Informal learning, which reflects the individualization of learning, can enable an organization to deal with workplace learning.
\end{abstract}

Keywords: Construct, industry 4.0, eight wastes, workplace learning, informal learning

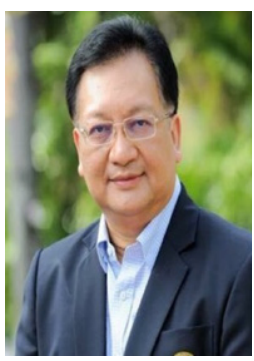

Dr. Bordin Rassameethes is the Associate Professor at Department of Operation Management, Faculty of Business Administration at Kasetsart University. He earned his doctoral study from University of Miami, Florida, USA. His research background and expertise include management of technology, competitiveness and international management, cluster management, digital integration, rural informatic, and information community.

${ }^{*}$ Corresponding author: Kongkiti Phusavat, Kasetsart University, Thailand. E-mail: fengkkp@ku.ac.th; ORCID: 0000-00022283-1118 


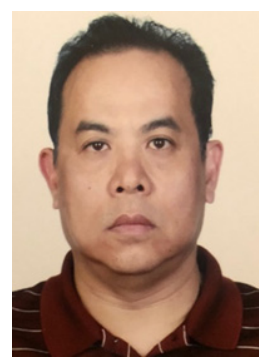

Dr. Kongkiti Phusavat is the Professor at Department of Industrial Engineering, Faculty of Engineering at Kasetsart University. He earned his master and doctoral degrees at Department of Industrial and Systems Engineering, Virginia Polytechnic Institute and Sate University or Virginia Tech. His research background includes productivity, industrial psychology, human learning, system design and development, and engineering education. Currently, he is the chairman of Education and Skills Committees of Joint Foreign Chambers of Commerce in Thailand.

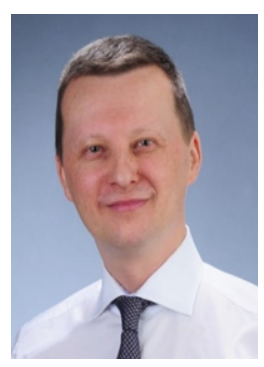

Zbigniew Pastuszak, Ph.D., Associate Professor; Vice-rector for development and business cooperation and the head of the MIS/SCM Department, Maria Curie-Sklodowska University, Poland. He has been serving in various consulting and teaching posts for more than 28 years. Professor Pastuszak has drafted and participated in grants from the Polish Science Committee, and the EACEA related to Polish competition in e-business, ereadiness, and multichannel logistics. $\mathrm{He}$ is the author of more than 90 international publications. Dr. Pastuszak serves as the Editor in Chief for the International Journal of Management and Enterprise Development and the International Journal of Value Creation Management.

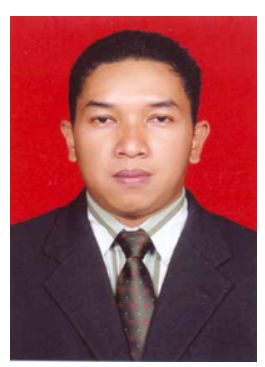

Dr. Achmad Nizar Hidayanto is the professor in Information Systems at the Faculty of Computer Science, Universitas Indonesia. He is also a Vice Dean for Resources, Venture, and General Administration. $\mathrm{He}$ received his bachelor's degree, master's degree and $\mathrm{PhD}$ degrees in computer science from Universitas Indonesia in 1999, 2002, and 2008 respectively. His research interests are related to e-health, information systems/information technology management, e-commerce, egovernment, information systems security, and information systems/information technology adoption. His email is " E-mail: nizar@cs.ui.ac.id."

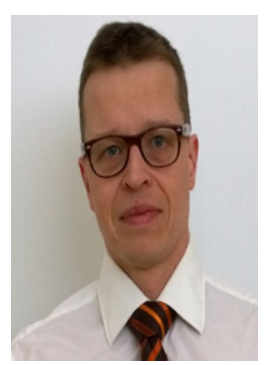

Jukka Majava (D.Sc., Tech.) is the Associate Professor in Industrial Engineering and Management at the University of Oulu, Finland. His industrial experience includes technology and ecosystem marketing, product and service development, project management, and business and supply chain development at Nokia Corporation. He has research interests in operations and supply chain management, innovation, learning, and business networks. His email is “E-mail: Jukka.Majava@oulu.fi."

\section{Introduction}

Industry 4.0 reflects a new philosophy that profoundly affects many issues in business operations, especially how a firm should view training education and human capital development [1,2]. Industry 4.0 typically brings the image of a smart factory and seamless operations with the use of advanced digital technology [1-3]. Optimizing work to achieve continuous high performance and competitiveness is often epitomized with this digitalization effort. Despite this prevailing perception, Industry 4.0 strongly also points toward a new expectation on the role of a worker in a globalized operation which relies on speed, efficiency, and responsiveness. This expectation cannot simply rely on digital technology alone. The human component in operations and work processes also need to adapt quickly to the changes in business environment. Many have highlighted the importance of adaptability to change, lifelong learning, teamwork and social interaction, and communication for future skills of the workforce in Industry 4.0 [4-6].

Industry 4.0 is a continuation from Industry 3.0 which began to integrate computer technology and automation in the early1970s [1]. The initial focus was on the manufacturing sector. Thus, knowledge, expertise, and technical skills were viewed to be critical for task or work completion. Training and education were still a viable option to upgrade a worker's capability and competence [7-9]. Training by external experts was believed to bring fresh ideas and represents more openness to the changes from the outside. Closed monitoring and evaluation became the key mechanism to ensure the effectiveness of the human capital development.

The transformation to Industry 4.0 helped integrate computer technology and automation into all key work processes within an organization $[1,2]$. Industry 4.0 is symbolized by extensive adaptations of robots, Internet of Things, machine learning, and 3D printing which became more visible in the late 2000s. Rapid utilization of unmanned technology (e.g., unmanned aerial vehicle) also reflect this shift. With the integration and advancement in technological applications, the workforce also needs to evolve along with this massive change. Simply put, the development of an organization's workforce is important to help maintain high performance $[10,11]$. Many activities and work process in Industry 4.0 constantly need active engagement of and inputs from the workers such as 
learning from customer interactions, engaging with suppliers, preventing repeated mistakes when performing the tasks, etc.

Many organizations recognize the importance of human capital development since not all operations can be digitalized. For instance, many successful firms have advocated the use of Thick Data along with Big Data [12]. Thick Data is qualitative data based on interactions, observations, reactions, and expression that provides insights into emotions which are the foundation of customer's needs. Often, unspoken gestures and stories are what matters to product and service customization. Thick Data compliments Big Data to help gain useful insights into customers' needs. Thus, learning is recognized as the vital component of Industry 4.0.

\section{Background}

Industry 4.0 has brought rapid changes in how individuals interact within and outside a workplace with co-workers, customers, suppliers, regulators, and competitors [7, 11, 13]. Transforming a workplace to deal with these ever- changing business environment and circumstance while achieving high performance remains the challenge. Many new problems facing an organization are becoming more complex and wicked due to more frequent disruptions and consequences (including pandemics, natural disasters, regulatory restrictions, trade barriers, etc.). Further, the effectiveness of product and service customization has compelled many organizations to take a closer look at their workforce and workplace [10, 14].

The workforce within the context of Industry 4.0 has dramatically changed from a traditional viewpoint which has emphasized the use of technical skills and knowledge to how the individuals can create their own knowledge [15-17]. This change signifies a different set of skills, especially learning how to learn, learning by teaching, etc. Moreover, the workers are expected not only understand how to perform the tasks but to continuously learn and improve their work $[16,18]$. For instance, a worker is expected to understand the needs of individual customers by learning through repeated observations and interactions (i.e., conversations and body language).

Furthermore, connectivity in digital technologies has impacted a great deal on inter-operational management. This impact highlights how various functional units within an organization operate and interact which also include the partnership with suppliers, contractors, regulators, civic groups, and customers. Moreover, user-generated contents by a worker have been encouraged since it is faster to help improve a worker's performance (e.g., avoiding repeated mistakes and confronting new tasks) than a traditional classroom training $[5,19]$. The expectations of being fast, flexible, proactive, and responsive imply the different roles and expectation of traditional workers in today workplace. New expectations on the workers such as multi-tasking and learning have become more common when discussing a future workforce for Industry 4.0 [5, 19, 20].

Training and education appear to be too reactive for a workforce's preparation due to a preparation needed when faced with a problem or a crisis. Although the knowledge is important, higher expectation on learning capability appears to be more prominent in a workplace today $[9,21,22]$. Due to the digitalization of work processes (as part of Industry 4.0), a development of a social platform (part of informal learning which is based user-generated contents) to strengthen knowledge sharing and transfer is presently common for many organizations $[17,23]$. This development points to the need to reexamine how the workers learn in an organization and also how fast they can learn in a workplace.

\section{Research question}

Given the rapid changes in business environment, what impact has the transition into Industry 4.0 had on training practices for human capital development within an organization? This question points to the need to evaluate how a worker is prepared for future work which will become more complex and uncertain $[1,2,14]$.

\section{Problem statement}

Many ongoing developments from several academic areas and business practices have been identified and recognized which are essential for successful business operations in Industry 4.0. A lot of investment has been made to upgrade the use of digital technology (e.g., workplace digitalization). However, the issues relating to the development of human capital, especially learning in a workplace and among individual workers have not been clarified which is needed for Industry 4.0. 


\section{Objective}

The study aims to determine the impacts and changes in human capital development when facing a transition into Industry 4.0. This determination is based on both practical and conceptual data which includes ongoing practices and recent available survey findings that have taken place within an organization. The construct is a primary output from this study. It is expected to help develop the construct for future studies on workplace learning.

\section{Significance of the research}

Recognizing the waste of human talents is critical for preparing a workplace for turbulent business environment and often-changing customer expectations. A traditional viewpoint on training as a foundation to retrieve the talents of an organization's workforce should be reexamined in parallel with the transition of an organization into Industry 4.0. Industry 4.0 has brought drastic changes in how an organization operates, responds, and reacts to customer expectations and business environment. Problems and challenges in a workplace can be expected to take place anytime so how a worker is prepared to deal with these problems and challenges is part of this transition. Operating successfully in Industry 4.0 certainly needs continuous workplace learning. This learning will likely determine business performance and competitiveness.

\section{Methodology}

The study can be classified as action research which is commonly applied in social sciences. This method is suitable when observing a transformative change and transition through a comprehensive gathering and understanding of relevant data. This data needs to highlight fundamental changes in environmental settings and to provide suitable directions or courses of actions to help address these changes. Observing and analyzing related data are the foundation for critical reflection when a set of environmental factors is identified. Instead of controlling these factors, the study intends to observe and notice how the environmental factors have changed and try to predict their impacts on the operations of an organization [4, 32]. To help verify the suitability of these impacts, a comparison with similar studies or findings is needed.
In this study, many factors are external and internal in nature such as a typical problem facing an organization's workforce in Industry 4.0, a speed in which this problem needs to be addressed and tackled- given an increasing level of competition and customer expectation, a need to better utilize the human talents in a workplace, and a decreasing proportion of knowledge needed to complete a task. These factors are essential within the context of human capital development when an organization strives to excel in Industry 4.0 $[1,2,12,14]$. They represent a premise in which data collection from relevant sources will be conducted and analyzed. Both practical and conceptual data will be included so that a prediction of a shift or a change is sound and credible.

\section{Findings}

To help achieve the study's objective, the practical and conceptual data will be viewed as an attribute that has contributed to a change in human capital development during an organization's transition into Industry 4.0. In this study, there are three attributes that have impacted the perception of training and development in a workplace. First, it is generally accepted that a problem facing an organization has become more complex and wicked $[2,16,25]$. Traditionally, a problem can be categorized as: (1) simplea problem is known and understood with an agreed solution, (2) complex- a problem is known and understood but can be resolved by many solutions, or (3) wicked- a problem is not fully understood so there is no clear solution. Multi-tasking, instead of focusing entirely on task specialization, is expected in a workplace since the best way to handle the complex and wicked problem is based on a worker's learning capability and opportunity. This viewpoint can also be illustrated with the use of Kaizen during the early 1980s. Note that Kaizen became popular because many Japanese auto manufacturers actively searched for incremental or gradual improvement ideas from their assembly line workers with the aim to improve quality and productivity $[1,26]$.

To maintain business success while continuously dealing with complex and wicked problems, lean and agile operations is essential [4]. Thus, the focus has been on tackling the wastes in an organization's operations and work processes. In the past, only Seven Wastes were recognized as the key contributors to low performance in terms of quality, productivity, and efficiency. These wastes included defects, over- 
production, waiting, transportation, inventory excess, motion, and excess processing [27].

As production and manufacturing had become more advanced along with increasing competition and global trades, minimizing operational wastes was one of the primary strategy objectives of an organization. For instance, due to the fluctuation of currency exchange rate (e.g., Japanese Yen to US\$ during 1980s and 1990s), massive efforts were underway to help reduce operational wastes reduction and to maintain lean operations. Recently, the underutilization of the workplace's talents was added to the traditional Seven Wastes [25, 28]. This new waste reflects the inability to utilize available talents of the workforce. This was singled out at the waste of all wastes facing most organizations today, especially those having to adapt to Industry 4.0.

This additional waste highlights the need to look beyond production and operational processes and recognizes the importance of human learning in a workplace [26, 28]. To remain competitive in an era of Industry 4.0, a productive workplace needs to show that all eight categories of wastes can be effectively handled and minimized. This is essentially a core principle in lean operations. In a typical firm, being lean is a prerequisite for profitability as waste represents poor planning and an unnecessary use of resources. Organizational wastes represent an expense which does not add value to products and services. Industry 4.0 requires the workers to be inspired and motivated endlessly as an organization needs to be responsive and adaptive. See Fig. 1 for the traditional Seven Wastes and the addition on unused talent.

The second attribute which has affected the viewpoint on training and development is based on the 70-20-10 concept. Th concept reflects an acceptance of a new role of a worker and how he or she can improve work since, within Industry 4.0. This concept is based many important developments in the past two decades. For any type of work, learning can take place anywhere and anytime with anybody within and outside an organization [13, $29,30]$. How the individual workers learn depends on learning environment, technology, culture, and social interactions [30]. Specifically, social interactions are important because these interactions reflect an opportunity to learn from each other. For the numerical reference of the 70-20-10 framework, 70\% of learning comes from hands-on or actual experience, experimentation, and self-reflection. $20 \%$ of learning stems from working with others through constant communications and collaboration. $10 \%$ of learning is based on career development planned by an organization.

- For the $70 \%$ component, it is known as learning by working and hands-on experience. This description indicates an opportunity for a worker to solve a problem (as he or she is trusted and empowered), to undertake challenging tasks or work, to be given an opportunity to review his or her work.

- For the $20 \%$ component, it is known as learning by working together and constant feedback. This description indicates an opportunity for a worker to constantly give and receive feedback during work, to observe and to coach others, and to be mentored.

- For the $10 \%$ component, it is known as learning by formal training and education which points to a series of courses, modules, seminars, and workshops. Also, a worker can learn in a classroom or register for e-Learning. Solutions are provided to a worker with follow-up assessment and test. This $10 \%$ learning portion is viewed as

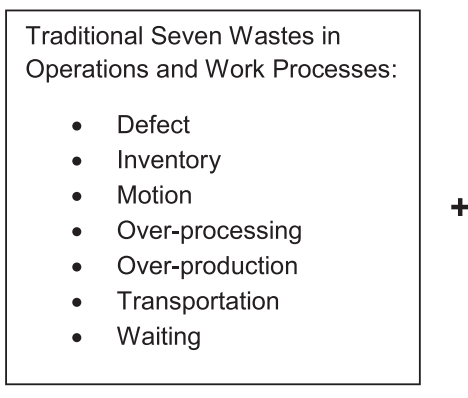

Waste \# 8: Unused talent- underutilization of talent, skills, and knowledge of the workers within an organization

Within the context of Industry 4.0: Waste in underutilizing the ability to learn or learning skills among the workers for complex and wicked problems when performing the tasks and work.

Fig. 1. Illustration of Eight Wastes within an Organization. 
part of regulatory compliance and career development (e.g., to qualify for a position requires a certificate or a passing grade). See Fig. 2.

The third attribute is based on the existing findings from previous surveys which clearly shows the change in how training and development are viewed. These past studies reveal many insights relating to workplace learning. The first issue is about the use of knowledge to perform and complete the tasks. The gradual decline of the impacts from training and education has been very significant and visible. Within one decade, the importance of knowledge provided directly by an organization became drastically less. In 1986, for a typical worker, $75 \%$ of knowledge needed to complete a task was provided directly by an organization. However, for the same context, the number went down to about 8-10\% in 2006 [31].

It appears that the ability to learn by a worker is perceived to be more crucial since this ability allows a worker to create or generate new knowledge needed for the tasks and work [20, 32, 33]. Due to the customization of products and services, a problem relating to customers can become unique and immediate which could be difficult for an organization to effectively prepare and respond. Learning by interacting with the customers, by observing and learning from the peers, and building the confidence in their learning ability have been essential for an organization in an era of Industry 4.0. Moreover, it is a challenge to prepare a training program on learning since standardizing the contents on learning for all workers is almost impossible. It is recognized that training is more suitable when dealing with uniform problems that are dealt by most or all workers. Training primarily provides knowledge which would become less helpful when business environment rapidly and constantly changes.

Another previous survey clearly points to the shift towards the importance of workplace learning. 84\% of business executives viewed learning as an important $(40 \%)$ or very important $(44 \%)$ issue while recognizing that ongoing activities, initiatives, and programs for training are not currently effective [34]. Interestingly, almost $50 \%$ of workers express their enjoyment and excitement about learning new skills and knowledge during work or working hours [35]. This existing survey highlights that learning can take place anywhere at any time (and should not rely on training). It also indicates that the workers increasingly perceive learning as part of their work. This notion is further supported by another survey which shows the workers usually spent about $35 \%$ on an average of their time on learning, especially with their peers and colleagues. Over $80 \%$ of the workers participate some forms of informal learning activities. For instance, user-generated contents for informal learning have been widely practiced $[30,36]$.

These three attributes have apparently underlined the need to have a new construct for workplace learning which relies less on training and development. This proposed construct is created by recognizing the impacts from the above attributes (i.e., organizational wastes, the 70-20-10 concept, and the surveys on the perception of the workers and management). Apparently, the focus on human-capital development has shifted from training and education to learning. For an organization to be successful in an era of Industry 4.0, a worker is expected to perform the tasks productively and to learn at the same time. Learning includes an understanding of past mistakes, a recognition of potential mistakes, an interaction with

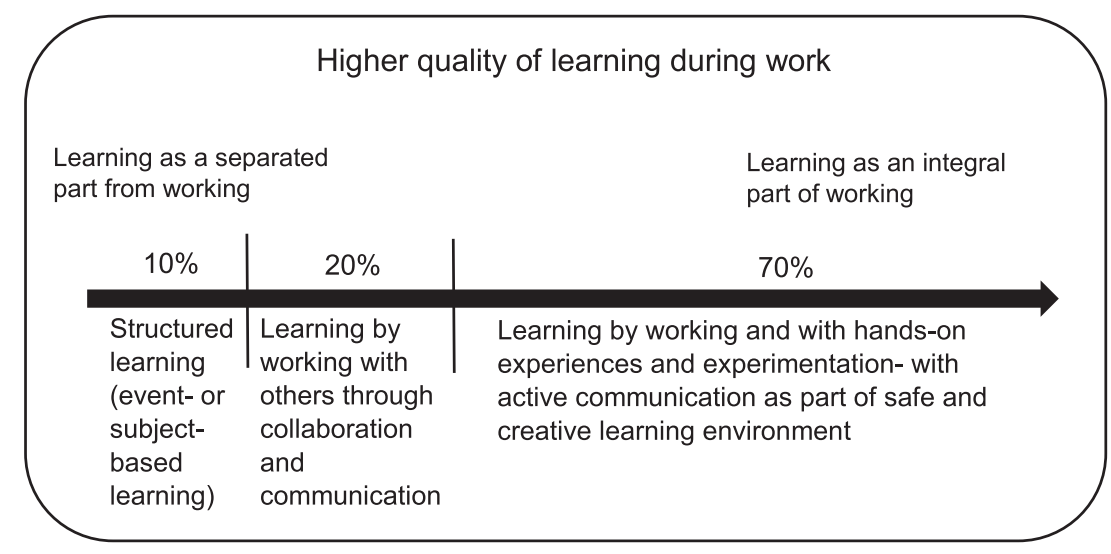

Fig. 2. Illustration of the 70-20-10 Concept. 
peers and colleagues, an interpretation of customers' behavior and reactions, and an insight into a possible response when facing a work-related disruption from a supplier [1, 11, 32].

Training on learning can be problematic because not all workers are faced with a same set of a problems. Thus, facilitating workplace learning and paying the attention to informal learning have become the priority [30, 36, 37]. This shift can start with how an organization views its workforce and whether an organization recognizes the workers' talents, especially learning ability. Thus, how individual workers learn within a workplace has been gaining a lot of interests since a successful organization need be able to respond and adapt to current business environment [27, 32, 38]. See Fig. 3.

\section{Discussion and contributions}

To support the notion that the shift from training to learning is inevitable when an organization needs to excel in Industry 4.0, the discussion focuses on comparing the proposed construct with other previous studies and their past results and conclusions. Future workplace learning has been influenced by the shift from training and development as highlighted by the three attributes mentioned earlier. This shift is based on the premise that learning is recognized as an integral part of work [19, 37, 39]. Recognizing the value and contributions of learning (e.g., to come up with creative idea and suggestion and to teach and share experiences other workers) that a worker can bring into a workplace is essential when an organization is faced with the transition into Industry 4.0.
This recognition is not completely new. In the early 1980s when Japanese products such as automobiles and electronic goods became known globally for high quality. Many Japanese manufacturing firms used the Kaizen concept to gather suggestions and ideas from their frontline workers on incremental improvements to existing work processes and operations [26, 28]. A success in small- step improvements in work processes needs the inputs and suggestions from the workers continuously.

The use of Kaizen is closely associated with the improvements in work processes, working environment, and products suggested by the workers. These improvements take place in an iterative or gradual way in an inclusive or participative manner. Thus, the Kaizen concept represents one of many earlier attempts to recognize the importance of learning in a workplace as individual workers were expected to contribute more than task completion. More importantly, the Kaizen concept has consistently stressed the importance of collaboration among the workers on solving operational-related problems. This approach is vastly different from relying on an expert's opinion to analyze and provide a solution which the workers were required to follow and comply $[1,26,28]$. The Kaizen concept illustrates that an organization could become more innovative through better utilization of the workers' talents (in this case, it was their hands-on experiences and problem familiarity).

Despite the success in the top-down approach for adapting digital technology and automation in a workplace, a shift from training to learning is inevitable. For an organization to succeed in Industry 4.0, the workers are generally expected to constant

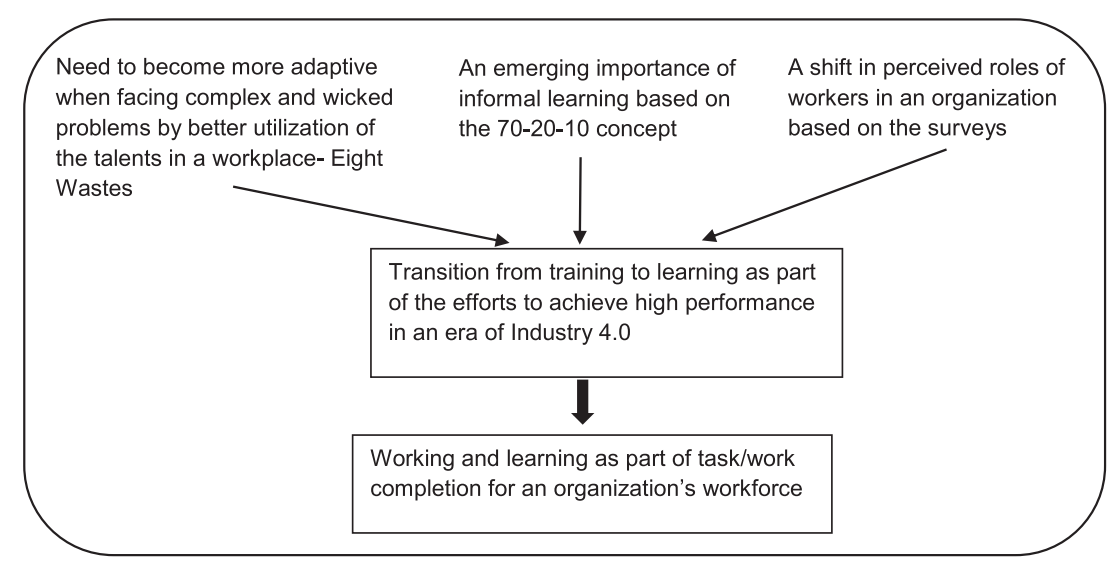

Fig. 3. Construct for Workplace Learning. 
innovate how they work. Moreover, there is an expectation that these workers can learn from their past work or experiences. They can bring up creative ideas to help enhance the value-added provided by an organization to its customers $[35,36]$. Value-added, according to Asian Productivity Organization, is an economic term to express the difference between the value of goods and the cost of materials or supplies that are used in producing them. Simply put, value added reflects a creation of wealth (Value Added $=$ Sales - Bought-in Materials and Services). Wages, salaries, interest, depreciation, rent, taxes, and profit reflect the term value added. New ideas and suggestions from the workers are important for possibly adding the value of goods (which is reflected by what customers are willing to pay) and minimizing cost of materials (e.g., a compatible substitute, sourcing, etc.).

For the proposed construct, workplace learning relies more on informal learning. This notion is consistent with many reports on the need to better facilitate learning for an organization's workforce $[10,25]$. Informal learning has emerged as an alternative to support continuous learning of as well as motivation to learn for the workers [40, 41]. Informal learning is based on the main idea that the workers can learn by interacting and receiving feedback with their colleagues and understanding more about the tasks by hands-on experiences. Facilitating learning (providing learning opportunity) instead of providing training and education becomes essential for successful informal learning.

Workplace learning is not simple because training and learning are vastly different. Workers are expected to follow what they are taught during training. Training is often used when a problem is simple and understood and its solution is known and accepted $[19,40]$. Thus, training tend to overlook the workers' ability to learn (i.e., overlooking the potential talents to learn and suggest improvements). Furthermore, training cannot be expected to catch up with the speed of change and new knowledge emerged during Industry $4.0[1,19,40]$. This notion is further supported by another survey's finding which shows that more than $75 \%$ of the executives express their concern about the ability to learn and grow whether it is fast enough to keep up with the needs and future of a business $[1,2]$.

The shift towards workplace learning is also influenced by the recognition of learning diversity. Due to this learning diversity, the effectiveness of training and education has become diminished. As previously mentioned, training aims to provide the knowledge needed to perform the work or to complete the tasks. However, because of the nature of the work in an era of Industry 4.0, knowledge can be quickly obsolete as the customization of products and services has compelled the workers to learn and improve their work constantly. This proposed construct is consistent with the latest efforts to tackle a failure to fully utilize the workplace's talents which is needed to help maintain successful lean operations. Dealing with learning diversity needs the insights into workplace engagement. This learning diversity implies a different level of the motivation to learn and a need to strategize how individual workers can be effectively engaged $[30,39]$.

The workers today need to engage more closely with their customers, suppliers. Since learning is an integral part of work, the need to recognize the difference between training and learning becomes even more important. Often, training is planned under a premise of readiness, willingness, and capability among the workers [5, 29]. However, recent surveys on a workforce have found that the level of engagement affects the quality of training and can impact on learning capability. Thus, it is essential that training and learning are viewed differently.

Focusing on learning indicates the importance of workplace engagement [19, 25, 32, 36]. The workers are classified as three groups- engaged, non-engaged, and disengaged. An engaged worker often expresses high satisfaction with a workplace. He or she can show some leadership during work and can lead when faced with a crisis. An engaged worker is aware of how to complete the tasks in the best possible manner and is likely willing to take up a challenge at work now or in the future. The reason is that an engaged worker is keen to learn and to be prepared for any unforeseeable situation at work.

A non-engaged worker primarily focuses on completing the tasks with some efforts but does not show any interests on learning. Thus, training is required when there is a new task at work. A disengaged worker is expected to provide minimum efforts and is not interested in learning (or even training). A disengaged worker does not add any value to improve customer experiences. As a result, a failure to consider the feeling of engagement can negatively affect the ability to utilize the talents in an organization and workplace learning. Often, standardized training is one of many prominent factors that has led to workplace disengagement $[37,42]$. This is due to a failure to recognize the importance of learn- 


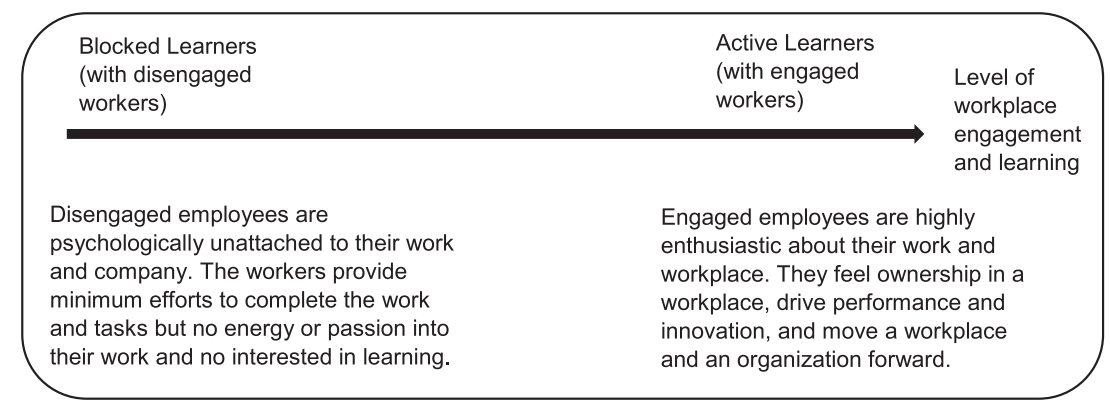

Fig. 4. Learning Diversity in a Workplace.

ing diversity and a need for constant feedback (as part of learning). In general, managing learning in a workplace today resembles to some extent a classroom in which the diversity in the learners needs to be recognized from learning capability to learning environment and culture [43, 44]. This recognition is critical for workplace learning. See Fig. 4.

To counter the negative impacts from the disengaged workers, an organization typically needs to achieve a 4-to-1 ratio of engaged to disengaged employees [42]. This ratio shows that while an organization focuses its efforts on strengthening customer engagement, workplace engagement can also have the same or even greater impacts on business success $[1,16,26]$. Unfortunately, the number of workers who are disengaged outnumbers the engaged workers by 2 to 1 which points to a very serious problem in culture and leadership as well as an ability to learn and adapt in changing business environment and circumstances. Informal learning appears to have positive impacts on increasing the level of engagement. Thus, workplace engagement becomes a priority in human-capital development since it directly impacts on learning and workplace's performance.

Finally, the proposed construct on workplace learning recognizes the inevitable shift from training for an organization operating in an era of Industry 4.0. Training presumes that a worker's motivation and learning diversity are not a serious matter. This is due to a basis that a worker is ready and is willing to implement what he or she is trained to perform the work or tasks. However, for learning, the context is greatly different. Learning is undertaken by a worker while training needs to be organized by an expert or an engineer and later is to be provided to a worker. The prevailing gap between learning and training which affects the speed to respond to customer requirements, business environment, and competition is the primary concern. This concern contributes to an underlying reason for more attention on workplace learning in the recent years $[6,20$, 29]. Facilitating workplace learning based on the different levels of workplace engagement will continue to be a challenge for human-capital development for years to come.

\section{Conclusion}

For an organization to become lean and agile successfully in an era of Industry 4.0, it is important to recognize the need to tackle the underutilization of the talents in a workplace. A worker today is expected to perform more than merely completing the assigned tasks. He or she is expected to perform the tasks and to learn and improve these tasks at the same time. Simply put, learning has become an integral part of work. This has prompted a shift from training and education to learning. Given the advancement of digital technology which allows the workers to interact with an organization's key stakeholders and to develop their personal contents based on hands-on experiences and feedback/ interactions with their peers, learning can easily take place. This represents an emerging practice, so called informal learning (part of the 70-20-10 framework).

From the proposed construct, workplace learning is clearly influenced by many disciplines such as human resource management, education, engineering, and psychology. Workplace learning focuses on how the individuals learn which deals with quality of work life, feeling of engagement, motivation and behavior, leadership, organizational culture, etc. In fact, workplace learning points to the transdisciplinary study due to ever- increasing complex working environment and business circumstance. The upcoming challenge of transforming various types of workforces (i.e., blue-, white-, and knowledge workers) 
into learning workers represents a new frontier of the research and academic work for the next several decades.

\section{Acknowledgments}

The authors have no acknowledgments.

\section{Author contributions}

CONCEPTION: Kongkiti Phusavat

METHODOLOGY: Kongkiti Phusavat

DATA COLLECTION: Kongkiti Phusavat

INTERPRETATION OR ANALYSIS OF DATA:

Bordin Rassameethes, Zbigniew Pastuszak, Achmad

Nizar Hidayanto and Jukka Majava

PREPARATION OF THE MANUSCRIPT: Kongkiti

Phusavat and Bordin Rassameethes

REVISION FOR IMPORTANT INTELLECTUAL CONTENT: Kongkiti Phusavat, Bordin Rassameethes, Zbigniew Pastuszak, Achmad Nizar Hidayanto and Jukka Majava

SUPERVISION: Kongkiti Phusavat and Bordin Rassameethes

\section{References}

[1] Masood R, Pareto L. Workplace work-integrated learning: supporting industry 4.0 transformation for small manufacturing plants by reskilling staff. International Journal of Lifelong Education. 2021;40(1):5-22.

[2] Tortorellaa G, Vergarab A, Garza-Reyes J, Sawhneyd R. Organizational learning paths based upon industry 4.0 adoption: An empirical study with Brazilian manufacturers. International Journal of Production Economics. 2020; 219(1):284-94.

[3] Severo E, Becker A, Guimarães J, Rotta C. The teaching of innovation and environmental sustainability and its relationship with entrepreneurship in Southern Brazil. International Journal of Innovation and Learning. 2019;25(1):78-105.

[4] Brix J, Jakobsen H. Corporate creativity: introducing the Creative Idea Solution@framework. International Journal of Innovation and Learning. 2013;13(4):388-405.

[5] David S, Hill C. Curriculum innovation for postgraduate programs: perspectives of postgraduate learners. International Journal of Innovation and Learning. 2020;28(3): 297-316.

[6] Deep S, Salleh B, Othman H. Study on problem-based learning towards improving soft skills of students in effective communication class. International Journal of Innovation and Learning. 2019;25(1):17-34.

[7] Muijs D, Rumyantseva N. Coopetition in education: collaborating in a competitive environment. Journal of Educational Change. 2014;15(1):1-18.
[8] O'Riordan F. Transformational pedagogy through curriculum development discourse, International Journal of Innovation and Learning. 2018;23(2):244-60.

[9] Zhao Y, Lu Y, Wang X. Organizational unlearning and organizational relearning: A dynamic process of knowledge management". Journal of Knowledge Management. 2013;17(6):902-12.

[10] Leitão,J, Pereira D, Gonçalves A. Quality of work life and organizational performance: workers' feelings of contributing, or not, to the organization's productivity. International Journal of Environmental Research and Public Health. 2019;16(20):3-18.

[11] Moustaghfir M, Ramid S, Touhs K. Linking human resource management, entrepreneurial orientation, and firm performance: an integrative theoretical framework. International Journal of Innovation and Learning. 2020;28(3):394414.

[12] Alles M, Vasarhelyi M. Thick data: adding context to big data to enhance auditability. International Journal of Auditing Technology. 2014;2(2):95-108.

[13] Edmondson A, Bohmer R, Pisano G. Disrupted routines: team learning and new technology implementation in hospitals. Administrative Science Quarterly. 2001;46(4): 685-716.

[14] Snihur Y. Responding to business model innovation: Organizational unlearning and firm failure. The Learning Organization. 2018;25(3):190-8.

[15] Chan K, Yung B. On-Site pedagogical content knowledge development, International Journal of Science Education. 2015;37(8):1246-78.

[16] Keller J. Motivational design for learning and performance: The ARCS model approach, Springer, New York; 2010.

[17] Vihari N. Effects of business model innovation on corporate sustainability: intervening role of organisational learning and strategic flexibility. International Journal of Innovation and Learning. 2019;26(2):131-54.

[18] Hislop D, Bosley S, Coombs C, Holland J. The process of individual unlearning: A neglected topic in an under-researched field. Management Learning. 2014;45(5): 540-60.

[19] Harlen W, Crick R. Testing and motivation for learning, assessment in education: principles. Policy \& Practice. 2003;10(2):169-207.

[20] Decius J, Schaper N, Seifert A. Informal workplace learning: development and validation of a measure. Human Resource Development Quarterly. 2019;30(4):495-535.

[21] Luthans F, Peterson S. Employee engagement and manager self-efficacy: implications for managerial effectiveness and development. Journal of Management Development. 2002;21(5/6):376-87.

[22] Wentzel K. Student motivation in middle school: The role of perceived pedagogical caring. Journal of Educational Psychology. 1997;89(3):411-9.

[23] Vollmeyer R, Rheinberg F. A surprising effect of feedback on learning. Learning and Instruction. 2005;15(6):589-602.

[24] Reason P, Bradbury H. The SAGE Handbook of Action Research: Participative Inquiry and Practice, SAGE Publications, London, 2008.

[25] Karasek A. Influencing innovativeness of enterprises by selected HRM practices. International Journal of Innovation and Learning. 2020;28(1):98-118. 
[26] Maarof M, Mahmud F. A review of contributing factors and challenges in implementing Kaizen in small and medium enterprises. Procedia Economics and Finance. 2016;35: 522-31.

[27] American Society for Quality. What is Lean? [Internet]. Milwaukee: ASQ; 2021 [updated 2021 January 28; cited 2021 February 8]. Available from https://asq.org/qualityresources/lean as of February 2021.

[28] Thiele-Schwarz U, Nielsen K, Strenfors-Hayes T, Hasson H. Using kaizen to improve employee well-being: results from two organizational intervention studies. Human Relations. 2017;70(8):966-93.

[29] Clardy A. 70-20-10 and the Dominance of informal learning: a fact in search of evidence. Human Resource Development Review. 2018;17(2):153-17.

[30] Johnson S, Blackman D, Buick F. The 70:20:10 framework and the transfer of learning, Human Resource Development Quarterly. 2018;29(4):483-402.

[31] RapidBI. Training and Learning and Development is Dead for Knowledge Workers. [Internet]. London: WordPress Website by The BBS Agency; 2021 [updated 2021 January 8; cited 2021 February 18]. Available from https:// rapidbi.com/training-learning-development-is-dead/.

[32] Argyris C. Teaching smart people how to learn. Harvard Business Review. 1991;69(3):99-109.

[33] Kluger A, DeNisi A. The effects of feedback interventions on performance: a historical review, a meta-analysis, and a preliminary feedback intervention theory. Psychological Bulletin. 1996;119(2):254-84.

[34] Pelster B, Haims J, Stempel J, Vyver B. Learning: Employees Take Charge. [Internet]. New York: Deloitte Insights; 2016 [updated 2016, February 28; cited 2021 March 12]. Available from https://www2.deloitte.com/us/en/insights/ focus/human-capital-trends/2016/fostering-culture-oflearning-for-employees.html.

[35] PR Newswire. Workers Expect Supervisors to Help Them Build Skills Continuously and In-Person, Showcasing the Importance of Employee Mentorship Programs. [Internet]. Chicago: Cision US; 2019 [updated 2019 August 26; cited 2021 March 23]. Available from https://www.prnewswire. com/news-releases/workers-expect-supervisors-to-helpthem-build-skills-continuously-and-in-person-showcasingthe-importance-of-employee-mentorship-programs300906546.html
[36] Győri A, Czakó A. The impact of different teaching methods on learning motivation - a sociological case study on Hungarian vocational education, International Journal of Innovation and Learning. 2020;27(1):1-18.

[37] London M, Larsen H, Thisted L. Relationships between feedback and self-development, group and organization. Management. 1999;24(1):5-27.

[38] Violato C, Lockyer J, Fidler H. Changes in performance: a 5 -year longitudinal study of participants in a multi-source feedback programme. Medical Education. 2008;42(10): 1007-13.

[39] Sutton R, Hornsey M, Douglas K. Feedback: the communication of praise, criticism and advice, Peter Lang Publishing: New York; 2012.

[40] Soraya D, Moustaghfir K. International faculty, knowledge transfer, and innovation in higher education: A human resource development perspective. Human Systems Management. 2019;38(4):423-31.

[41] Wasin A, Wei W. Employee innovativeness, fairness and organizational support: An empirical assessment. Human Systems Management. 2019;38(2):169-77.

[42] Brim B. How a Focus on People's Strengths Increases Their Work Engagement [Internet]. Atlanta: Gallup; 2019 [updated 2019 May 2; cited 2021 April 26]. Available from https://www.gallup.com/workplace/242096/focus-peoplestrengths-increases-work-engagement.aspxas

[43] Dermol V, Mirazchiyski E, Trunk A, Çayır K. Teachers' competencies for working in an intercultural environment, Human Systems Management. 2021; Pre-press: 1-11.

[44] Konte A, Xiaohui L. How mindfulness impacts the positive forms of leadership and enhances performance at workplace. Human Systems Management. 2021;40(1):49-64. 